\title{
Integrating scan mobile with electronic signage solution in supermarket and retail store
}

\author{
Ho Trung Thanh, Tran Duy Thanh
}

\begin{abstract}
Nowadays, supermarkets or retail chains are increasingly interested in how to increase productivity at their stores. The problem here is that prices, promotions and product information updates need to be immediate. Building an electronic signage solution that uses interactive mobile Internet of Things (IoT) technology including technology for Electronic Commerce to Opticon Electronic signage solutions (ESL) devices allows stores, supermarkets to change product prices in real time and launch promotional campaigns at Any time or place as desired. The system has been widely deployed in Vietnam market. ESL helps eliminate traditional labeling, labor saving, and other costs associated with price changes and product information, especially through mobile devices, users can easily change electronic prices quickly and conveniently. The solution of this article has been posted on http://opticon.vn.
\end{abstract}

Keywords-IoT, ESL, price of management, supermarket, e-commerce, opticon, mobile

\section{INTRODUCTION AND RESEARCH MOTIVATION}

\subsection{Abbreviations and Acronyms}

GOR years, barcode technology has been widely Fenjoyed and used in key industries such as healthcare, business, control. But it was not until 2005 that this technology was really developed and expanded its influence in Vietnam market. With the intelligent automatic management function, barcode scanners are becoming an essential factor for all aspects of life. Every type of business will be correspondent to a barcode scanner. So, we should select a suitable barcode scanner for industry and purposes of use, in order to maximize

Received: 18-7-2017, Accepted: 12-01-2018, Published: $15-$ 7-2018.

Authors Hồ Trung Thành, Trần Duy Thanh, University of Economics and Law, VNUHCM, Vietnam (e-mail: thanhht@uel.edu.vn). the functions of barcode scanner and support our business effectively. Currently, Vietnam's market has appeared many kinds of barcode scanners from different manufacturers, to meet the increasingly more diverse needs of consumers.

In recent day, the need for price changes, as well as displaying information about the product: promotion price, source of the product is increasingly demanded in higher, more modern and faster mode. With this trend, Opticon Company (the Dutch headquarters) has built warehouse overall management system for supermarket and retail store through the ESL system, using Internet of Things technologies to optimize all operations of the business. Vietnam Opticon has ordered us (the authors of Faculty of Information System, University of Economics Law, VNU-HCM) to build and integrate mobile software into ESL system to further improve the optimization process system for customers. The building and integrating support the ESL system to display the price of products placed on different shelves in Supermarket with synchronous method and change product prices on remote shelves when Supermarket has many branches.

\subsection{Research motivation}

As we know, nany supermarkets, chain stores, fashion shops ... in Vietnam and around the world are showing prices by paper label, we can easily see Coop Mart, Coop Food, VinMart, VinMart +, Lotte Mart, Big C,... or many different shops using paper and manual labels.

This is a great challenge to change the price listing or the promotion, spend a lot of manpower as well as financial costs and time to change all the information of the product in booth (Paper labels must be removed, printed and paste-back every day, even every hour). With surveys and market assessments, Opticon Company (the Dutch headquarters) has researched and deployed 
electronic signage solution (ESL) in major shops... supermarkets, convenience stores, and fashion

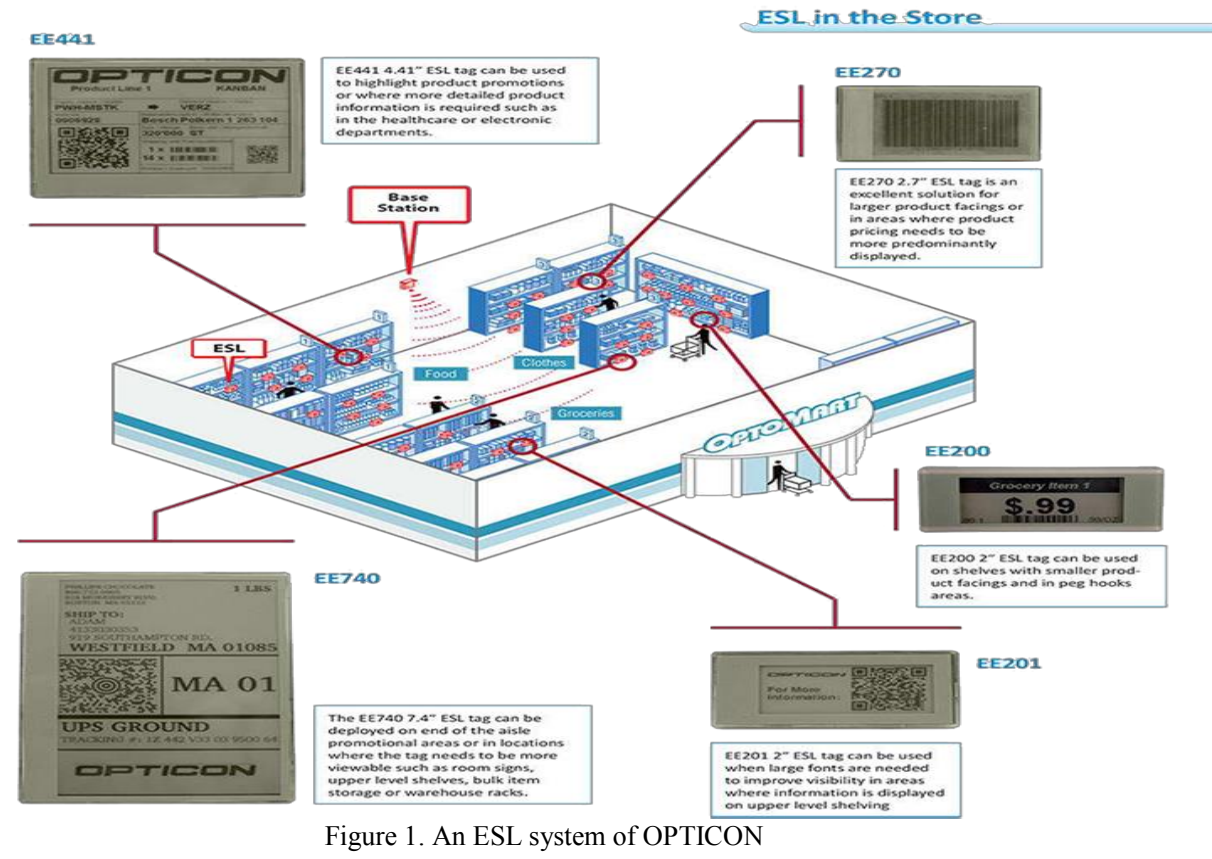

The system is operated as follows:

- Data Warehouse: this is the server where the customer database is stored. Database management system can be: MySQL, SQL Server, Oracle ...

- Opticon Base Station: in a supermarket, retail stores will be fitted with many Base Stations, this device has two tasks: First, the Base Station will connect and take data from the Data Warehouse, then output the data to the ESL, Base Station and ESL will communicate with each other automatically, they have their own IP address. When the ESL receives the signal, it displays pricing information and other information that the customer can view.

- Electronic Signage Device (ESL): each item will be associated with ESLs, each ESL will have an identifier (using an IP address) to connect to the Base Station. The main task of ESL: First, connect the Base Station to display the price and other information of the product such as pictures, promotions; Second, allow Link, supermarket will assign this product to the ESL; Third, allow Unlink, if not use, the supermarket will remove the connection between the ESL and the product. Link or Unlink are based on the product barcode database and ESL address.
- Network System: supermarkets and retailers need to build a network so that devices can easily connect to each other as well as connect to the database.

This system has the disadvantage that all communication must be through a desktop software or a website system to manage the connection between devices, as well as want to change the price must be done on the desktop software. This is a big obstacle because there are so many products in the Supermarket, the space is widespread, so it is very inconvenient when employees have to carry their computers to check the products We built the mobile system into the old model to improve as well as accelerate price changes in the fastest way for supermarkets and retail chain. The detailed solution will be presented in the following. In part 2, elementary theory; part 3 build and deployment solution; part 4 focuses on performance evaluation and discussion.

\subsection{Research questions and objectives}

\section{Research questions}

To integrate the scan mobile with electronic signage solution in supermarket and retail store, two partial questions are formulated: 
Question 1: How to display the price of products placed on different shelves in Supermarket with synchronous method?

Question 2: How to change product prices on remote shelves when Supermarket has many branches?

Question 3: What are the benefits when integrating and applying mobile into electronic shelf label system ESL?

Research Objectives

Solutions and Internet of Things System. The article focuses on Technical models for devices in IoT to communicate with each other:

- Telemetry: messages move one way from device to system. The goal is to send the device state to the system.

- Inquiry: sends device requests to the system. These requests involve gathering information that the current device does not collect. The information that is used to trigger an event is described in advance.

- Command: sends commands from the system to a device or group of devices to capture those devices for a specific task, and returns status results after execution.

- Notification: similar Telemetry information also moves one-way, but from the system to the device (reverse to Telemetry).

Electronic devices and mobile.

Price management processes, warehouse management, and management operations at the supermarket.

- The chain of supermarkets and convenience stores in Vietnam and the world that Opticon deploy.

\subsection{Research process}

Proceed to examine the chain of supermarkets and shops using paper labels or electronic labels from competitors in order to find out the needs as well as the missing parts of the system. From which build and improve the software system to respond the higher requirements of customers.

The Research \& Development (R \& D) department proceed research on trends in the use of technology and proposes directions to respond the ongoing development of technology as well as the needs of customers, from which the technical department will deploy the ideas and test the system.

The Q-A department (Quality Assurance) will continue to install the system and software manuals for customers as well as continue to receive feedback from customers' right when testing the system at the booth. The technical error requirements will be sent back to the technical department for processing, requests for new technology of customers will be sent to the R \& D department.

The marketing department will approach the bestselling products, receive positive feedback from the market, synthesize the problems and send them to R \& D for further feasibility studies.

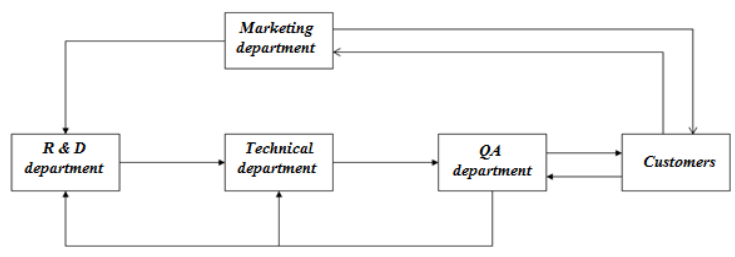

Figure 2. The process of coordinating research and development of the system

\section{ELEMENTARY THEORY}

\subsection{Internet of Things}

Internet of Things (IoT) is a field that represents next technological revolution after the Internet (D. Raggett, 2015). IoT will bring endless opportunities and impact every corner of our planet. IoT has evolved from the convergence of wireless technologies, micro-electromechanical systems, and the internet.

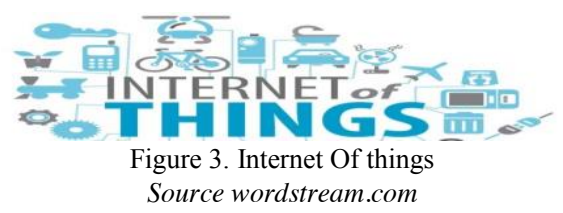

IoT has a lot of applications now and in the future, we can build smart, safe and energyefficient homes, smart shopping, smarthome, management and urban management planning. Marketing, environmental management, emergency response, personal device management, smart meter, and many other applications (Anne H. $\mathrm{Ngu}$ Mario Gutierrez, Vangelis Metsis, 2017). Many companies such as Cisco, Intel, and Qualcomm ... have sponsored IoT start-up, the profits from IoT projects are enormous.

According to Word stream, by 2020, the IoT will reach the following thresholds: 4 billion connected, \$ 4 trillion in revenue, more than 25 
million applications, more than 25 billion embedded systems and intelligent systems, 50,000 Billion gigabytes of data.

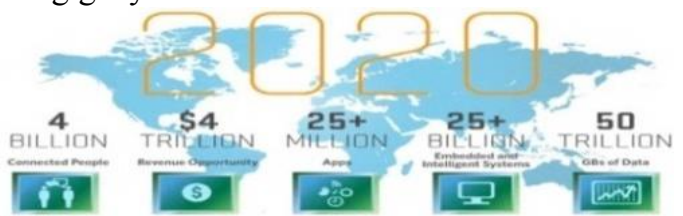

Figure 4. Regular users of the InternetInternet of Things 2020 Source wordstream.com

\subsection{Compressor solutions for applications in the system}

In order to be able to integrate strings, images, data into the electronic display of ESL equipment, we have to conduct research on many of the data compression techniques to apply. By studying IoT's solution, specifically the interactive solution between mobility and ESL equipment, mobile data retrieved from the ESL and products will automatically be transferred to the Data Warehouse, Data Warehouse will store data, from which the Base Station will hook into model into a type of data that ESL can display on the electronic screen. Here are some of the algorithms used in building the system.

\subsubsection{Dynamic Markov compression (DMC)}

This algorithm has the important task of putting Data Stream (or source message) in the Markov chain. A Markov chain, named after the Russian mathematician Andrei Andreyevich Markov, is a discrete-time random process with the Markov property. In such a process, the past is not related to predicting the future, it depends only on the knowledge of the present.

The Markov chain is a sequence of $\mathrm{X} 1, \mathrm{X} 2$, $\mathrm{X} 3, \ldots$ of random variables. The set of all possible values of these variables is called the state space $S$, the value of $\mathrm{Xn}$ is the state of the process at time $n$.

If the determination (forecast) of the conditional probability distribution of $\mathrm{Xn}+1$ gives that the past states are a function of $\mathrm{Xn}$ then:

$$
\begin{gathered}
\mathrm{P}(\mathrm{Xn}+1=\mathrm{x} \mid \mathrm{X} 0, \mathrm{X} 1, \mathrm{X} 2, \ldots, \mathrm{Xn})=\mathrm{P}(\mathrm{Xn}+1 \\
=\mathrm{x} \mid \mathrm{X} 0)
\end{gathered}
$$

Where $\mathrm{x}$ is a certain state of the process ( $\mathrm{x}$ belongs to the state space $\mathrm{S}$ ).

\subsubsection{Lempel-Ziv-Welch compression (LZW)}

This algorithm is responsible for compressing data in string, PNG, GIF and ZIP format (Lempel and Ziv, 1977). This method works on a very simple idea, the encoder and decoder build the encoding together. This encoding does not need to be included with the data during the compression process, but when decompressed, the decompressor will rebuild it. The most important part of this compression method is to create a dictionary to store the strings of the characters encountered. When the data bytes to be compressed are passed to the stored buffer and compared to the strings in the dictionary.

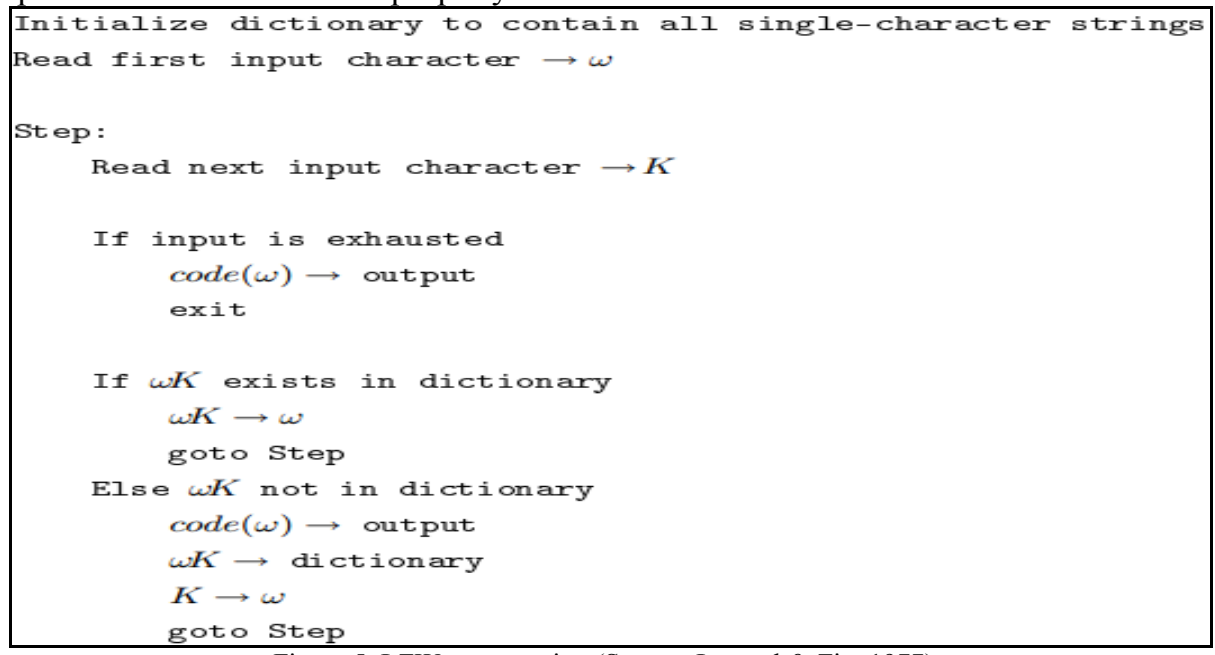

Figure 5. LZW compression (Source: Lempel \& Ziv, 1977) 
ESL's electronic screening system will combine these algorithms to display data. ESLs with this functionality will provide a very good customer experience.

\subsubsection{Move-to-Front Transform (MTF)}

\begin{tabular}{lll}
\hline Message & Alphabet queue & Position queue \\
\hline $\mathrm{a}$ & {$[\mathrm{a}, \mathrm{b}, \mathrm{c}, \mathrm{d}]$} & {$[0]$} \\
$\mathrm{ab}$ & {$[\mathrm{b}, \mathrm{a}, \mathrm{c}, \mathrm{d}]$} & {$[0,1]$} \\
$\mathrm{aba}$ & {$[\mathrm{a}, \mathrm{b}, \mathrm{c}, \mathrm{d}]$} & {$[0,1,1]$} \\
abaa & {$[\mathrm{a}, \mathrm{b}, \mathrm{c}, \mathrm{d}]$} & {$[0,1,1,0]$} \\
abaac & {$[\mathrm{c}, \mathrm{a}, \mathrm{b}, \mathrm{d}]$} & {$[0,1,1,0,2]$} \\
abaaca & {$[\mathrm{a}, \mathrm{c}, \mathrm{b}, \mathrm{d}]$} & {$[0,1,1,0,2,1]$} \\
abaacab & {$[\mathrm{b}, \mathrm{a}, \mathrm{c}, \mathrm{d}]$} & {$[0,1,1,0,2,1,2]$} \\
abaacaba & {$[\mathrm{a}, \mathrm{b}, \mathrm{c}, \mathrm{d}]$} & {$[0,1,1,0,2,1,2,1]$} \\
abaacabad & {$[\mathrm{d}, \mathrm{a}, \mathrm{b}, \mathrm{c}]$} & {$[0,1,1,0,2,1,2,1,3]$}
\end{tabular}

Figure 6. How to calculate MTF (Source: Bentley, Sleator, Tarjan \& Wei, 1986).

The idea of the MTF algorithm (Bentley, Sleator, Tarjan, and Wei, 1986) is data compression. The MTF algorithm is designed to improve the efficiency of Entropy encoding technique, creating the best compression data. MTF is used after the Burrows-Wheeler transform to rank the symbols according to their correlation frequencies.

\subsection{Materials and measured parameters}

\subsubsection{Materials}

The material used in the evaluation stages were promotion images created for DM3370. In total, twelve bi-level images with a size of $172 \times 72$ pixels were used to form a corpus set. It covers a wide variety of images that possibly could be used in the Prier ESL platform. The majority of the image show information of interest to customers.

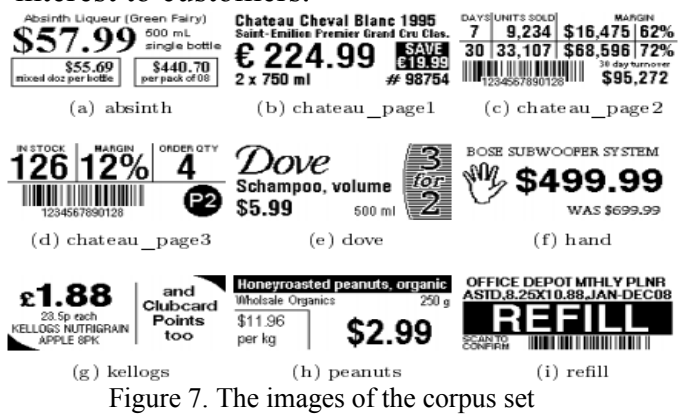

The purpose of the evaluation stages were to quantify the performance of the prototypes in different ways, the prototypes were written in Java and C.

TABLE 1 LIST OF PROTOTYPES

\begin{tabular}{cc}
\hline Prototypes & Short description \\
\hline Golomb RLE & Prototype sequences of zeroes were encoded using a Golomb-Rice code with parameter \\
\hline LZW & In the LZW prototype indices of the dictionary were appended to the output stream \\
using a variable-length code
\end{tabular}




\subsubsection{Measured parameters}

Compression factor: The compression factor is a measure of how much a compression scheme is able to reduce the size of a data stream. The compression factor $\mathrm{F}$ is defined by $F=\frac{\| x_{\text {in }} \mid}{\left|x_{\text {out }}\right|}$, where $\left|x_{\text {in }}\right|$ is the length of the input binary data and $\left\|x_{\text {ort }}\right\|$ is the length of the output binary data of a prototype.

Encoding and decoding Time

Measurements: The time measurements of the encoding and decoding phases of a porotype were conducted by repeating the same experiment 100 times per image. An experiment consisted of starting the timer, starting the prototype and stopping the timer, where the time elapsed was the result of a timing experiment. The result of a prototype experiment using a specific image was the average value of the timing experiments.

Memory Consumption: The memory consumption was measured by analyzing the prototypes' decoding functions in terms of statically allocated arrays. If applicable, a prototype's decoding function written in $\mathrm{C}$ was analyzed.

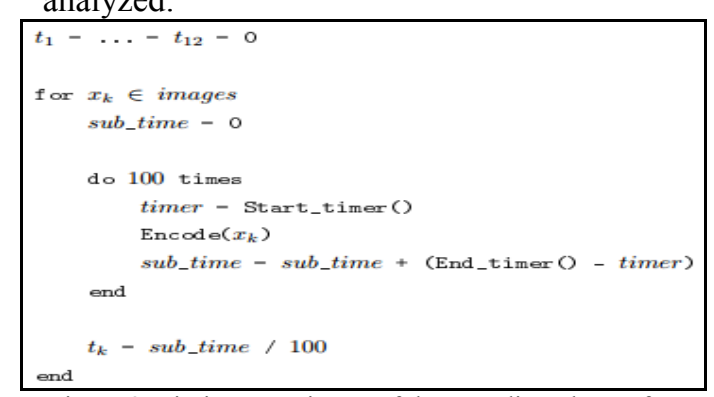

Figure 8. Timing experiment of the encoding phase of prototype

\section{IMPLEMENTING SOLUTION}

An implementation of a compression scheme is called a prototype, reflecting the basic functionality of an implementation. A prototype fulfills two criteria: the first criterion requires the prototype to be fully runnable with respect to the encoding and decoding phases, the second criterion requires the prototype to produce valid results.
The input data used by the prototype are fed as a continuous bit stream in a raster scan format, where each bit represented a bit-level pixel value. Prototypes are based on character compression used alphabet extension to read input data. In this case, alphabet extension is based on reading a binary input stream in substrings to create a suitable context. Character-based prototypes will read eight bits at a time in blocks of $2 \times 4$ pixels and formed a character of those bits.

The DMC (2.2.1) prototype, find the Low and High current interval. With any string message, we need to find the current interval via Low and High value to display on the screen device, for example: "hello" string.

With LZW (2.2.2) prototype indices of the dictionary are appended to the output stream using a variable-length code. Indices of the dictionary are written using binary notation in as many bits as specified by a code word length parameter. Initially the length parameter is set to 9 bits, but it is increased whenever the last index will exceed the maximum bits implied by the length parameter. The maximum code word length is 10 bits, implying that indices greater than 210 would not be uniquely decodable, because several code words will have the same least significant bits. Hence dictionary re-initialization is not done in the event of reaching a full dictionary. The prototype used a hash table as dictionary, where each entry is a pair of a string and an integer, holding the cumulative string and its index.

With MTF (2.2.3) prototype used an alphabet array consisting of all eight-bit characters initially sorted in lexicographical order. Each character from the input data stream is searched in a sequential order from the array. The position of a matched character, denoted position, is encoded using the Elias Gramma code. All elements from position to position are shifted one position to the right in the array, i.e: $\operatorname{array}[\mathrm{x}]$ is moved to $\operatorname{array}[\mathrm{x}+1]$. The final step is to set first element in the array to the matched characters. 


\subsection{Introduction solution}

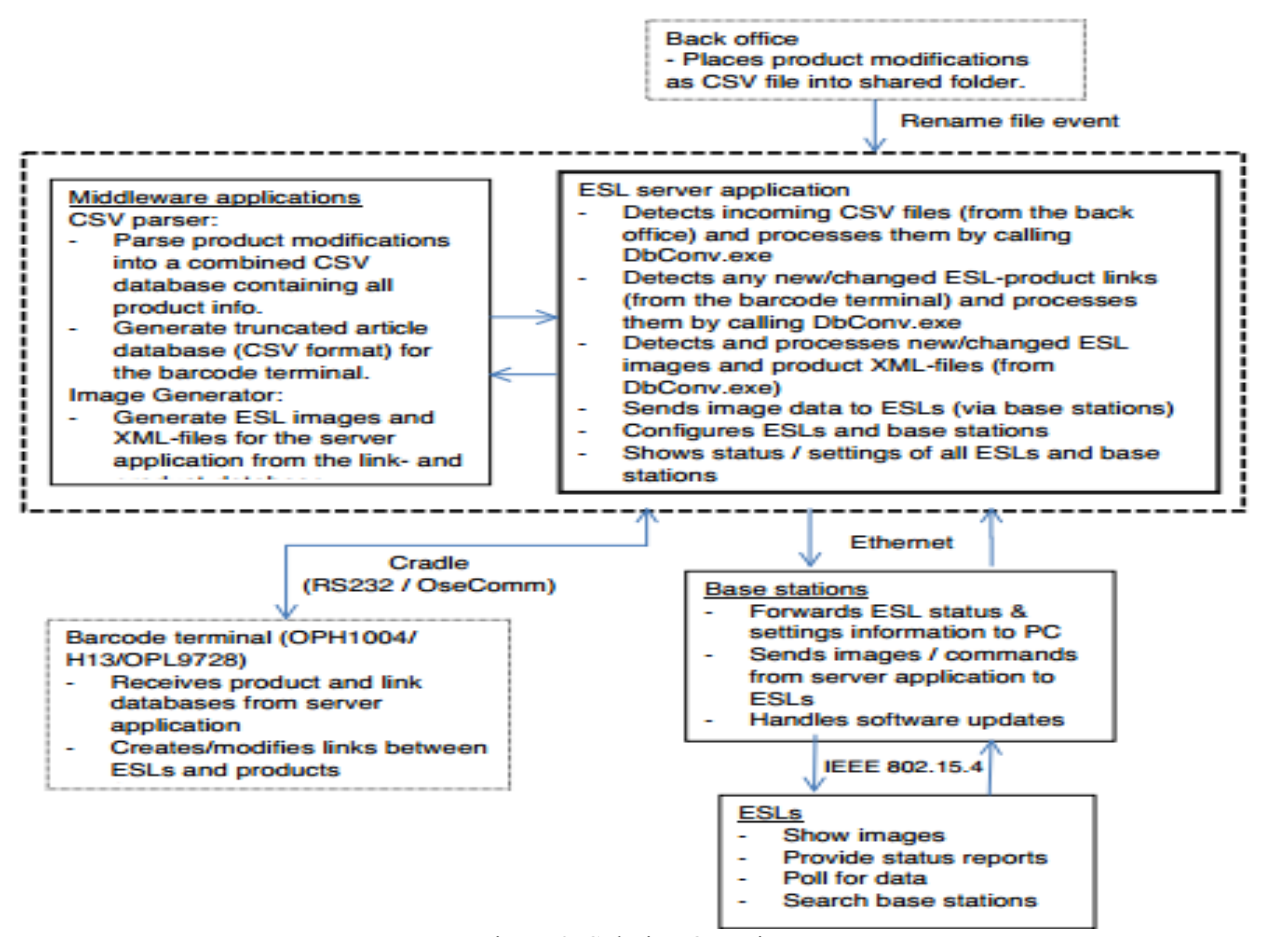

Figure 9. Solution Overview

The ESL solution works by: running the ESL Server application from the server. This application monitors and receives any change in the user-processed database (called back office system). Then, ESL Server will automatically process the changes and send to the ESL to display the results.

\subsubsection{ESL Status Information}

Each ESL will also periodically transmit the following status information.

TABLE 2

ESL STATUS INFORMATION

Status

Battery voltage
Explain

Current battery voltage
Boot counter

LQI
Number of times the ESL has been reset (automatically and manually)

Indicator of the signal strength from an ESL (from ESL to base station)

Indicator of the signal strength from an ESL (from base station to ESL)
LQI BS 16-digit MAC address of the ESL

\section{MAC}

Time of the latest poll that has been received from the ESL 


\subsubsection{Configuring the Ethernet Settings}

To set up the base station for use within an existing network, its DHCP configuration, IP address, and subnet masks need to be configured.

To prevent IP address conflicts when a base station is connected to a network, DHCP is enabled by default. On most installations, a fixed IP address setup is recommended. If DHCP is used, make sure the DHCP server always assigns the same IP address to the same base station.

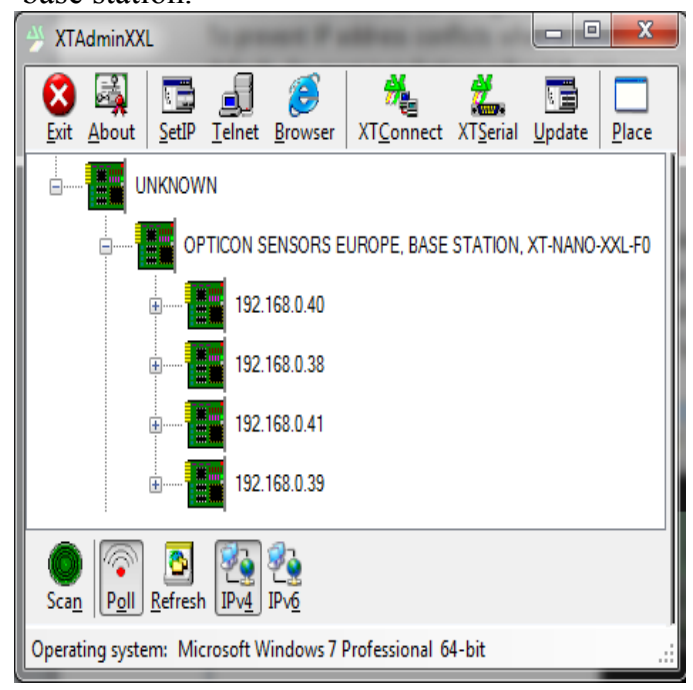

3.2 Integrating mobile into electronic shelf label system ESL

Applying ESL solution for Vinmart and Vinpro supermarkets of Vingroup Corperation. In this overall project, the first pilot for two supermarkets of Vinmart and Vinpro in Time City, Hanoi.

We build and integrate mobile software system to interact directly with the ESL electronic shelf label system in order to optimize the operation and time to use ESL for changing price, manage warehouse directly and efficiently (see Figure 11). Mobile devices with software installed will automatically connect to Opticon devices, allowing the ESLs to send a signal to the Base Station to link, unlink, price change of products and software, in addition to ability automatically generate the corresponding data tables with data stores of supermarkets and retail stores.

Main process steps in software system:

Step 1: Research SDK for mobile of OPTICON to connect the company's genuine scanner and barcode products of customers.

Step 2: Identification scans the IP/MAC address of ESL devices, this step is very complex and important to determine exactly genuine device and product line.

Step 3: Input the barcode scanning type of product, to connect ESL with product through barcode.

Step 4: Carry out the automatic update to Data Stores of Customer System for the Base Station can connect and transfer data to the right ESL on the shelf.

Step 5: Base Station devices (designed optimized network system) can retrieve data in Data stores, transfer data to ESLs. Every Base Station at the same time can transfer data to about 5000 ESL, so a big store can have many Base Stations that links together.

Step 6: ESL devices will automatically link with Base Station, automatically "shake hand" and "send the message" to each other. These ESLs take data from Base Station to shows a price and other information on the shelf. This automatically update information happen in real-time, ESLs seem immediately received a message when Data store changed.

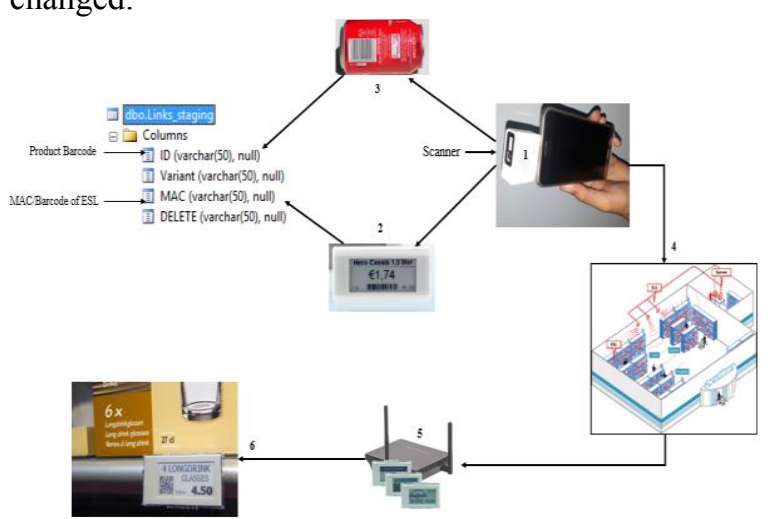

Figure 11. Model decay mount between barcode and ESL by mobile

Source: Opticon ESL RESULTS AND DISCUSSION

\subsection{Results}

In order to check the accuracy level of software, we conducted experiments on 100 stores with 1000 products and execution by the 8 standards, defined as follows:

Standard QA 1: Enough light, distance scan < $0.5 \mathrm{~m}$, clear camera is not covered by dust, strong network connection.

Standard QA 2: Enough light, distance scan < $0.5 \mathrm{~m}$, clear camera is not covered by dust, weak network connection.

Standard QA 3: Enough light, distance scan > $1 \mathrm{~m}$, clear camera is not covered by dust, strong network connection. 
Standard QA 4: Enough light, distance scan > $1 \mathrm{~m}$, clear camera is not covered by dust, weak network connection.

Standard QA 5: Enough light, distance scan < $0.5 \mathrm{~m}$, camera is covered by dust, strong network connection.

Standard QA 6: Enough light, distance scan < $0.5 \mathrm{~m}$, camera is covered by dust, weak network connection.

Standard QA 7: Enough light, distance scan > $1 \mathrm{~m}$, camera is covered by dust, strong network connection.
Standard QA 8: Enough light, distance scan > $1 \mathrm{~m}$, camera is covered by dust, weak network connection.

We recommend not experimenting in booth/data store which not enough light, light must enough to ensure health and vision of workers.

Experimental results (see table 3) at different stores is also give the similar results with each standard.

TABLE 3

EXPERIMENTAL RESULTS IN SCANNING ACCURACY

\begin{tabular}{cccc}
\hline Conditions & $\begin{array}{c}\text { Number of experimental } \\
\text { samples }\end{array}$ & $\begin{array}{c}\text { Number of successfully } \\
\text { experimental samples }\end{array}$ & $\begin{array}{c}\text { Number of failed experimental } \\
\text { samples }\end{array}$ \\
\hline Standard QA 1 & 1000 & 1000 & 0 \\
Standard QA 2 & 1000 & 1000 & 0 \\
Standard QA 3 & 1000 & 992 & 8 \\
Standard QA 4 & 1000 & 992 & 82 \\
Standard QA 5 & 1000 & 958 & 42 \\
Standard QA 6 & 1000 & 958 & 190 \\
Standard QA 7 & 1000 & 810 & 190 \\
Standard QA 8 & 1000 & 810 & 42 \\
\hline
\end{tabular}

The accuracy $=$ sum of successes/total samples of all Standards QA $=7520 / 8000=94 \%$. This result was passed by the QA Test.

From experimental results above, we conclude as the following about the quality of the software that corresponds to the experimental standards:

Software does not depend on strong or weak network connections (strong or weak also successful, if only weak, it takes time to wait fro).

Software depend on Camera is clear or not (recommended to clean the camera when not in use for a long time).
Software depends on Barcode's distance scan on ESL devices and products.

The most exact result should use software in Standard QA 1 or QA 2, we recommend customers use these two standards to perform, this also is justifiable requirements and very suitable for working environment.

The worst result when using software in Standard QA 7 and QA 8 (at a long distance and when camera is covered by dust), of course, customers should not use in bad condition. 


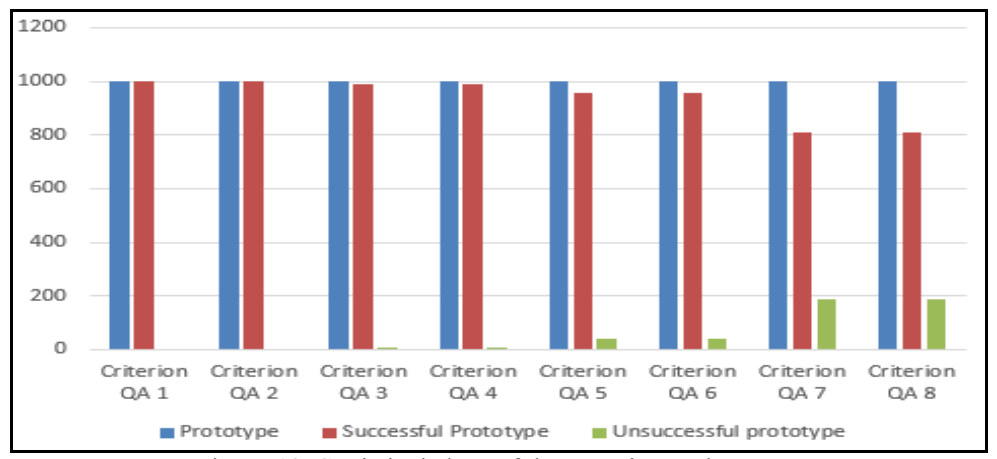

Figure 12. Statistical chart of the experimental process

In addition to the standard above, the system depends on the material of production also barcode printing on devices, because there are some reflective materials that make the camera very difficult to scan the barcode. However, this problem is on the side of the bar code manufacturers for the products, so it is not within the scope of the test of the development system.
3.4 Analyzing econonic benefits when aplying the solution

3.4.1Economic benefits when comparing with the competitors

Inputs: Store covering $1,800 \mathrm{~m}^{2}$, with 15,000 ESLs

Average gross salary: $\$ 17 /$ hour

TABLE 4

ECONOMIC BENEFITS WHEN COMPARING WITH THE COMPETITOR

\begin{tabular}{|c|c|c|c|}
\hline Parameters & Our ESL System & Competitor & Saving \\
\hline $\begin{array}{l}\text { Management of the IT } \\
\text { system }\end{array}$ & $\begin{array}{l}\text { Management of the application } \\
=\text { no intervention required }\end{array}$ & $\begin{array}{l}\text { Management of tables, } \\
\text { removal of ESLs from the } \\
\text { base, creation of faulty label } \\
\text { lists, etc. }=1 / 2 \text { hour / day }\end{array}$ & $\begin{array}{l}1 / 2 \mathrm{~h} \times \$ 17 \times 320 \text { days } \times 5 \\
\text { years }=\$ 13600\end{array}$ \\
\hline $\begin{array}{l}\text { In-store verification of } \\
\text { faulty label lists }\end{array}$ & $\begin{array}{l}\text { Radio signal which travels } \\
\text { through any, obstacle. Two-tier } \\
\text { antenna system which } \\
\text { guarantees that messages are } \\
\text { received = no verification } \\
\text { required }\end{array}$ & $\begin{array}{l}\text { In-store verification of faulty } \\
\text { label lists }==1 / 2 \text { hour / day }\end{array}$ & $\begin{array}{l}1 / 2 \mathrm{~h} \times \$ 17 \times 320 \text { days } \times 5 \\
\text { years }=\$ 13600\end{array}$ \\
\hline $\begin{array}{l}\text { Additional costs due to } \\
\text { remodeling }\end{array}$ & $\begin{array}{l}\text { No intervention required }=\text { no } \\
\text { additional costs }\end{array}$ & $\begin{array}{l}\text { Transmission equipment must } \\
\text { be moved = technical work } \\
\text { carried out at night }\end{array}$ & $\begin{array}{l}1 \text { remodeling every } 5 \text { years }= \\
\text { Cost of the work }=\$ 13,000\end{array}$ \\
\hline $\begin{array}{l}\text { Additional costs due to } \\
\text { label breakage }\end{array}$ & $\begin{array}{l}\text { Robust rail, protection of the } \\
\text { ESL by screen printing, theft- } \\
\text { proof ESL mounting system= } \\
\text { very little breakage and no loss } \\
\text { of ESLs }\end{array}$ & $\begin{array}{l}\text { Mounts or rails that provide } \\
\text { little } \\
\text { protection, no locking } \\
\text { system= breakage and loss of } \\
\text { ESLs }\end{array}$ & $\begin{array}{l}\text { Replacement of } 3 \% \text { of ESLs } \\
\text { each year }=450 \text { ESLs x } \$ 3 \times \\
5 \text { years }=\$ 6,750\end{array}$ \\
\hline $\begin{array}{l}\text { Additional costs for the } \\
\text { installation and removal of } \\
\text { labels }\end{array}$ & $\begin{array}{l}\text { "Easy Lock" mounting system, } \\
\text { which makes it easier to move } \\
\text { labels = Removal }+ \\
\text { reinstallation }=0.6 \text { seconds }\end{array}$ & $\begin{array}{l}\text { Not very ergonomic } \\
\text { mounting system }=\text { Removal } \\
+ \text { reinstallation }=3 \text { to } 4 \\
\text { seconds }\end{array}$ & $\begin{array}{l}30 \% \text { of the } 15,000 \mathrm{ESLs} \\
\text { handled/year }=15,000 \mathrm{x} \\
30 \% \times 3 \mathrm{~s}=3.45 \mathrm{~h} ; 3.45 \mathrm{~h} \times \\
\$ 17 \times 5 \text { years }=\$ 318.75\end{array}$ \\
\hline TOTAL & \multicolumn{2}{|c|}{$\begin{array}{l}\text { Total savings on operating costs in } 5 \text { years } \\
\text { with the Competitor vs Our ESL system }\end{array}$} & $\sim \$ 47,300$ \\
\hline
\end{tabular}




\subsubsection{Economic benefits when comparing with paper label}

Inputs: ESL system will be used in 7 years (the battery life is 7 years if each day the ESL tag changes price one time). Suppose that the supermarket has at least 180,000 types of product. Every day, they will change price 5 times for 30,000 products. So, the paper label which they need to use for this to be $30,000 * 5=150,000$ paper label in one day. But in fact, the times of price changing and the number of products need to be updated to be very large. This hypothesis is suggested at a minimum. Following is the comparing table of the cost deployment between ESL system and paper label.

TABLE 5

THE COMPARING OF THE COST DEPLOYMENT BETWEEN ESL SYSTEM AND PAPER LABEL

\begin{tabular}{|c|c|c|}
\hline Parameters & ESL & Paper label \\
\hline \multirow[t]{2}{*}{ Base station } & $200 \$ / 1$ unit $* 5=1000 \$$ & \multirow{2}{*}{0} \\
\hline & $=22,722,500 \mathrm{~d}$ & \\
\hline \multirow[t]{2}{*}{ ESL Tag 2 inch } & 30,000 unit $* 7 \$=210,000 \$$ & \multirow{2}{*}{0} \\
\hline & $=4,771,725,000 \mathrm{~d}$ & \\
\hline \multirow[t]{4}{*}{ Printer } & \multirow{4}{*}{ 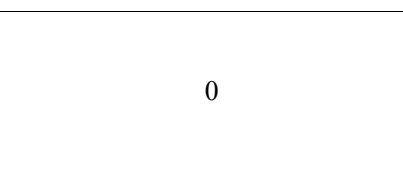 } & $50,000,00 \mathrm{~d} /$ unit \\
\hline & & High performant printer 1 unit/year \\
\hline & & The cost for 7 years: \\
\hline & & $7 * 50,000,000=350,000,000 \AA$ \\
\hline \multirow[t]{6}{*}{ Ink printer } & \multirow{6}{*}{0} & Ribbon ink: 110,000/roll. With 1 roll, we can print for 5000 labels \\
\hline & & About 150,000 paper labels in a day. \\
\hline & & The ink cost for a day will be: \\
\hline & & $(150,000 / 5,000) * 110,000=3,300,000 đ$ \\
\hline & & The cost for 7 years: \\
\hline & & $7 * 365 * 3,300,000=8,431,500,000$ đ \\
\hline \multirow[t]{5}{*}{ Paper label } & \multirow{5}{*}{0} & A cheap paper label roll is 50,000 d for 1000 labels \\
\hline & & The cost for paper label in a day: \\
\hline & & $(150,000 / 1000) * 50,000=7,500,000 \mathrm{~d}$ \\
\hline & & The cost for 7 years \\
\hline & & $7 * 365 * 7,500,000=19,162,500,000$ đ \\
\hline \multirow[t]{5}{*}{ Employee cost } & \multirow{5}{*}{0} & $\begin{array}{l}5 \text { people/ day, their permission will be finding } \& \text { changing product } \\
\text { information for } 30,000 \text { products. }\end{array}$ \\
\hline & & Hypothesis is that we have to change 150,000 labels/ day. \\
\hline & & The hiring employee cost is $5,000,000 \mathrm{~d} /$ person in Vietnam. \\
\hline & & The cost for 7 years: \\
\hline & & $7 * 12 * 5 * 5,000,000=2,100,000,000$ đ \\
\hline TOTAL COST & $\begin{array}{l}4,794,447,500 \text { đ } \\
\text { Saving cost: } 30,044,000,000- \\
4,794,447,500=25,249,552,500 \text { đ }\end{array}$ & $30,044,000,000$ đ \\
\hline
\end{tabular}

\subsubsection{Absolute price integrity}

Be $100 \%$ sure that your price labels display the correct price at the shelf edge. Eliminate manual errors, increase customer loyalty, and have complete control over your price adjustments. It's cost-effective and easy to maintain. ESL are wireless, fast and secure. Update store prices immediately: Quickly and reliably update pricing in-store. With the fastest, most reliable solution, you can be certain your products are selling at the correct price. No delay.

Reduce pricing errors: Eliminate pricing errors. Your price labels in-store will match your back-end database, and the prices in the checkout counters, at all times. Plus, no more price audits. With electronic labelling you will 
be $100 \%$ confident that the prices on the shelf match your back-end database.

Improve customer loyalty: With correct prices, your customers will shop confidently in your store, knowing the likelihood of delays and queries once they reach the checkout are greatly reduced. Your employees can spend more time helping your customers.

Confirmation of price updates: ESL system is a two-way communications solution that updates prices and reports back to confirm the updates have been made. Monitor the success of your updates from the back office, or at head office. It's effortless. Stress-free.

Eliminate fines \& price audits: Prices in your database are what's on display at the shelf edge. You've got more control, whether it's for promotions or regular item prices. It just works.

No lost sales from unpriced goods: With electronic price labels all items in-store will have a price - if not, your system will notify you that there's a problem.

\section{CONCLUSION AND RECOMMENDATION}

ESL is the most advanced technology solution, with a high-security level, power saving, infrared with maximum speed, ESL time of use is up to 7 years, can operate in severe weather from -22 to 55 $\mathrm{C}$ degrees. A ESL Server can transfer data to 5000 ESL devices clients, this is one of the advantages that the project coordinated between the company and the Faculty of Information Systems, University of Economics - Law wants to bring to customers. With the combination of a mobile system to speed up information manipulation as well as price updates, it makes it easy for supermarkets and retail chains to manage, reducing the cost of printing documents also labour costs. We will continue to improve the system to allow users to scan barcodes under worse conditions such as a scan distance of more than $1 \mathrm{~m}$, dusty dirt or barcode printing materials with reflective material.

In the future, we are integrating into the EKB consumer behaviour model (Engel, Kollat \& Blackwell, 1984) is seen as a continuous process that involves identifying needs, collecting information, analyzing evaluations, and making decisions. This process is influenced by internal factors and external factors such as input information, information processing process, engine, environment and etc. Information gathering and environmental impact are two factors influence on final decision making. Procurement usually starts with consumers recognizing their needs, which can be realized when customers are impacted internally or externally and they will conduct information gathering about the product, the brand based on personal experience and the external environment, then compare the price to decide whether to buy the product or not. Besides, based on data derived from the ESL system and data collected from consumers' behaviour through the OPN-2006 device, we will build intelligent data analysis system (Business Intelligence) to support businesses in making sales decisions, analyzing consumer behaviour, identifying purpose \& marketing strategies, keeping customers valuable, and predicting potential customers.

\section{Acknowledgement}

This research is funded by Vietnam National University (VNU-HCM) under grant number C2017-34-03. We would like to express our gratitude to the experts and the $\mathrm{BI}$ LAB Centre of the Information Systems Department of the University of Economics and Law, VNU-HCM for supporting us in the process of research and development.

\section{REFERENCES}

[1]D. Raggett, The Web of Things: Challenges and opportunities, IEEE Comput., vol. 48, no. 5 (2015).

[2] Anne H. Ngu Mario Gutierrez, Vangelis Metsis, IoT middleware: a survey on issues and enabling technologies. IEEE Internet of Things Journal, vol. 4, Issue: 1, Pages 1 20 (2017).

[3] Alberto Apostolico and Aviezri S. Fraenkel, Robust Transmission of Unbounded Strings Using Fibonacci Representations, IEEE Transactions on Information Theory, Vol. 33, No. 2 (1987).

[4] Jon L. Bentley, Daniel D. Sleator, Robert E. Tarjan, and Victor K. Wei, A Locally Adaptive Data Compression Scheme, Communications of the ACM, Vol. 29 No. 4, pages 320-330 (1986).

[5]Gordon V. Corrmack and R. Nigel Horspool, Data Compression Using Dynamic Markov Modelling, The Computer Journal, Vol. 30, No. 6, Pages 541-550 (1987).

[6] Jacob Ziv and Abraham Lempel, A Universal Algorithm for Sequential Data Compression, IEEE Transactions on Information Theory, Vol. 23, No.3, Pages 337-343 (1997).

[7]Michael Dipperstein, Burrows-Wheeler, Transform Discussion and Implementation (2009).

[8] Engel, James F., David T. Kollat and Roger D. Blackwell, Consumer Behavior, Hinsdale, Il.: The Dryden Press (1978). 


\title{
Giải pháp tích hợp dán nhãn điện tử bằng di động cho siêu thị và cửa hàng bán lẻ
}

\author{
Hồ Trung Thành*, Trần Duy Thanh \\ Trường Đại học Kinh tế - Luật, ĐHQG-HCM \\ *Tác giả liên hệ: thanhht@uel.edu.vn
}

\author{
Ngày nhận bản thảo: 18-7-2017, Ngày chấp nhận đăng: 12-01-2018; Ngày đăng: 15-7-2018
}

Tóm tắt-Ngày nay siêu thị hay các chuỗi cửa hàng bán lẻ ngày càng quan tâm hơn đến việc làm như thế nào để gia tăng năng suất hoạt động tại cửa hàng của họ. Vẩn đề ở đây là giá cả, chương trình khuyến mãi và cập nhật thông tin sản phẩm cần được tức thời. Xây dựng giải pháp nhãn giá điện tử sử dụng các công nghệ IoT và thương mại điện tử tương tác di động tới các thiết bị Opticon ELS cho phép các cửa hàng, siêu thị thay đổi giá sản phẩm theo thời gian thực và thực hiện các chiến dịch khuyến mãi tại bất kì thời gian hoặc địa điểm theo mong muốn. Hệ thống đã được triển khai phổ biến tại thị trường Việt Nam. Giải pháp nhãn giá điện tử ESL giúp loại bỏ phương pháp dán nhãn truyền thống, tiết kiệm nhân công và các chi phí phát sinh khác khi thay đổi giá cả và thông tin của sản phẩm, đặc biệt thông qua thiết bị di động thì người sử dụng có thể dễ dàng thay đổi giá điện tử một cách nhanh chóng và tiện lợi nhất. Giải pháp này đã được đăng tải trên http://opticon.vn.

Tù khóa-IoT, ESL, quản lý giá, siêu thị, thương mại điện tử, opticon, di động. 